\title{
A Proposed Approach for Prioritizing Maintenance at NASA Centers
}

\author{
Steven C. Dunn ${ }^{\mathrm{a}}$ \\ Jacobs Technology Inc., NASA Langley Research Center, Hampton, VA, 23681 \\ Melvin H. Sawyer ${ }^{\mathrm{b}}$ \\ Jacobs Technology Inc., NASA Langley Research Center, Hampton, VA, 23681
}

\begin{abstract}
The National Aeronautics and Space Administration (NASA) manages a vast array of infrastructure assets across ten National Centers with a worth of at least 30 billion dollars. Eighty percent of this infrastructure is greater than 40 years old and is in degraded condition. Maintenance budgets are typically less than one percent of current replacement value (CRV), much less than the $2-4 \%$ recommended by the National Research Council. The maintenance backlog was 2.55 billion dollars in FY10 and growing. NASA's annual budgets have flattened and are at risk of being reduced, so the problem is becoming even more difficult. NASA Centers utilize various means to prioritize and accomplish maintenance within available budgets, though data is suspect and processes are variable. This paper offers a structured means to prioritize maintenance based on mission criticality and facility performance (ability of the facility to deliver on its purpose). Mission alignment is assessed using the current timeframe Mission Dependence Index and a measure of facility alignment with the 2011 NASA Strategic Plan for the long-term perspective. Facility performance is assessed by combining specific findings from a structured facility condition assessment and an assessment of actual functional output. These are then combined in a matrix to identify the facilities most critical to mission and able to deliver services. The purpose of this approach is to provide the best benefits for the available funding. Additionally, this rationale can also be applied to the prioritization of investment (recapitalization) projects so that the ultimate customers of this paper, the senior infrastructure managers at each NASA Center, are better able to strategically manage their capabilities.
\end{abstract}

\section{Introduction}

$\mathrm{T}$ HIS paper presents an improved (theoretical) approach to maintenance at NASA Centers that allows tailored investment based on facility alignment with mission and current facility performance. NASA faces huge challenges in infrastructure management due to aging infrastructure (much of it in degraded condition), changing and uncertain mission definition, technology growth requiring new investments, large maintenance backlogs (deferred maintenance), a wide variety of asset types, low current workloads in some ground test, research, and launch facilities, and declining budgets. The current approach of trying to accomplish all planned preventive maintenance while making increasingly frequent and costly repairs to aging equipment has become untenable. An aggressive effort to reduce costs and backlog by shutting down some facilities while accomplishing repair by replacement of others will address only some of the challenge. Remaining facilities and their capabilities must be managed and sustained to meet mission needs, both near- and long-term. This requires an improved approach for maintenance services that tailors scope (and associated cost) to prioritized needs.

This paper will provide a brief overview of the serious infrastructure challenges NASA is facing. This is followed by a discussion of NASA maintenance practices, providing a foundation for aligning maintenance processes with needs and budgets. Then the point of the paper is presented - a methodology to manage assets in a budget-constrained environment.

\footnotetext{
${ }^{a}$ Chief Engineer, ROME Group, NASA Langley Research Center, Mail Stop 267, Hampton, VA, 23681, Senior Member.

${ }^{\mathrm{b}}$ Plant and Facilities Engineering Manager, ROME Group, NASA Langley Research Center, Mail Stop 485, Hampton, VA, 23681.
} 


\section{Current State of Infrastructure at NASA Centers}

Some excerpts from a recent (March 2011) audit of NASA's facilities maintenance ${ }^{1}$ :

"Many of NASA's facilities are in degraded condition and its maintenance backlog continues to grow each year. NASA's deferred maintenance estimate for all its facilities increased from $\$ 1.90$ billion in fiscal year (FY) 2005 to $\$ 2.55$ billion in FY 2010. Continued deferral of facility maintenance could result in unsafe working conditions and higher annual maintenance costs. From FY 2005 through FY 2009, deferred maintenance as a percentage of current replacement value increased, indicating that NASA's facilities were deteriorating."

"Problems associated with NASA's ability to maintain its facilities and associated infrastructure have been widely reported for more than 2 decades. In 1990, the Government Accountability Office (GAO) reported that many of NASA's facilities were in degraded condition and had not been adequately maintained."

"More recently, the Aerospace Safety Advisory Panel (ASAP) expressed concern about the safety of NASA's infrastructure. ASAP's Annual Report for 2010 stated that 'although the Field Centers appear to be doing a good job in identifying facilities that have deficiencies that could pose a safety risk to employees or missions, the Agency still has not presented a systematic approach to prioritizing facilities and laboratories requiring safety-related repairs and harmonizing funding across the Agency to facilitate those repairs in the most effective manner."'

“. . . a 2010 National Research Council assessment reported that NASA must invest more in maintaining and upgrading its basic research laboratories if it wants to meet major mission goals."

“. . . we found that much of NASA's construction of facilities (CoF) funding is for major repair work. This could indicate that maintenance and repair funding is insufficient at the Centers."

In August 2011, a NASA Office of Inspector General (IG) reports begins²:

"NASA's real property holdings include approximately 5,000 buildings and structures such as wind tunnels, laboratories, launch pads, and test stands. In total, the assets occupy 44 million square feet and represent more than \$26.4 billion in current replacement value. However, 80 percent of NASA's facilities are 40 or more years old and many are in degraded condition. Moreover, NASA is dealing with the challenge of its aging infrastructure at a time of large and growing budget deficits that are straining the resources of all Federal agencies. As discretionary funding continues to decline, NASA will be required to make more prudent decisions regarding its infrastructure."

The cost to sustain the capability of facilities and real property has grown as the asset base has grown and aged. Even as an asset divestment process (demolition of low use assets) is accelerating, sustainment costs for remaining assets continues to grow. Each building, facility, wind tunnel, and laboratory has a designed life cycle based on expected use and an expected maintenance schedule. Over time, the functional performance of the facility will degrade, with the rate being affected by the efficacy of preventive maintenance (PM) and any required repairs. As an asset degrades, availability of the asset's capability declines and maintenance costs increase as repair needs increase. However, with an effective preventive maintenance program and periodic recapitalization efforts, it is possible to sustain the asset life indefinitely. A pictorial of an asset life cycle is shown in Figure $1^{3}$. It can be observed from this figure that at some point, even with planned maintenance, performance degrades to unacceptable levels unless recapitalization investments are made. At this level of performance, it is not worth the cost of doing maintenance because of a low return on asset output. Additionally, life cycles can be shortened if less than needed maintenance is performed over time.

The NASA Associate Administrator for Mission Support presented a "NASA Facility Strategy" on May 10, $2011^{4}$. Some excerpts from that briefing:

"More than 80 percent of NASA's infrastructure and facilities by value are beyond their design life - thus more likely to be unsuitable for current and future missions." 


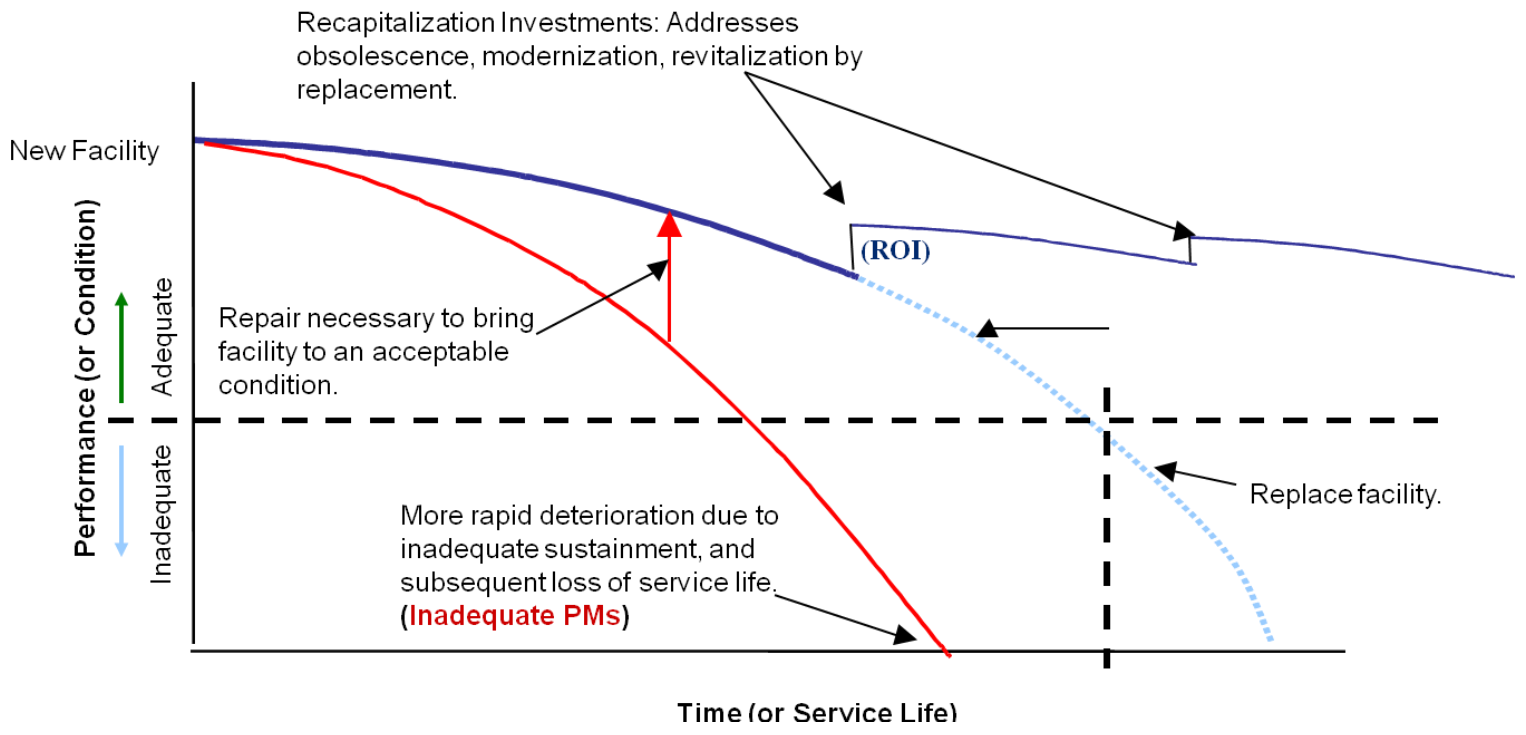

Figure 1. Asset Life Cycle.

"Deferred Maintenance has been rising since FY 2005 at rate of $\sim 9$ percent per year. Ratio of unplanned to planned maintenance continues to grow. Unplanned maintenance is much more expensive, resulting in even more deferrals of planned maintenance activities. Unscheduled outages and closures have disrupted current missions. NASA is unable to meet higher mandates for energy efficiency. Common facility problems such as water leaks, working/walking surfaces, and facility objects contribute to reported safety incidents."

"NASA's plan is to renew and modernize its facilities to sustain its capabilities to meet current and future mission requirements, and to accommodate those capabilities in fewer, more efficient facilities." (See Figure 2.)

Clearly, NASA is at a decision point in determining what they are going to do with a suite of aging assets in an environment of declining budgets and changing mission. Facilities have been created over the years to meet mission needs; even though many have been repurposed for new needs, this process has generated a vast array of different

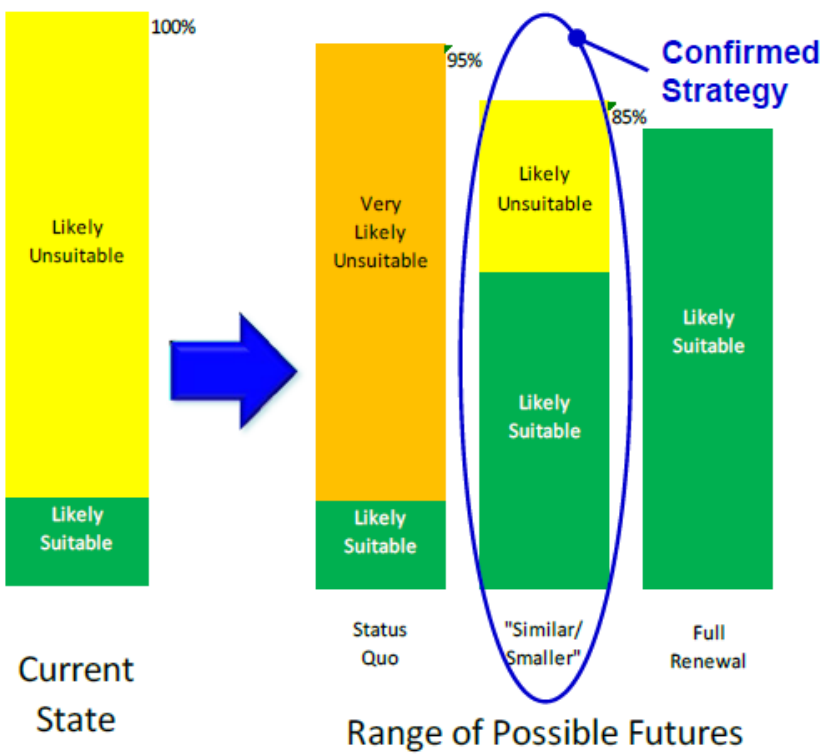

Figure 2. NASA Facilities Strategy. asset types and capabilities. The current (2011) budget enables about a third of this plan, requiring further consideration. One example in Dr. Whitlow's briefing looks at what could be sustained with a $\$ 150 \mathrm{M}$ per year recapitalization budget (Figure 3). This review separates constructed facilities into three categories and in blocks of $1 \%$ of the total (\$30B worth of total assets, so each block is worth $\$ 300 \mathrm{M})$. Under this scenario, only $25 \%$ of technical facilities are retained, dramatically reducing the current number of technical facilities.

The August 2011 IG report states that only one data source - the Real Property Management System (RPMS) - is designed to capture key information consistently across all Centers to complete required reports and to integrate real property data into the NASA financial system. The IG review focused on utilization, mission dependency, and condition since they are primary factors driving NASA's infrastructure 


\section{A Portrait of NASA's 4700 Constructed Facilities Assets by Valuation}

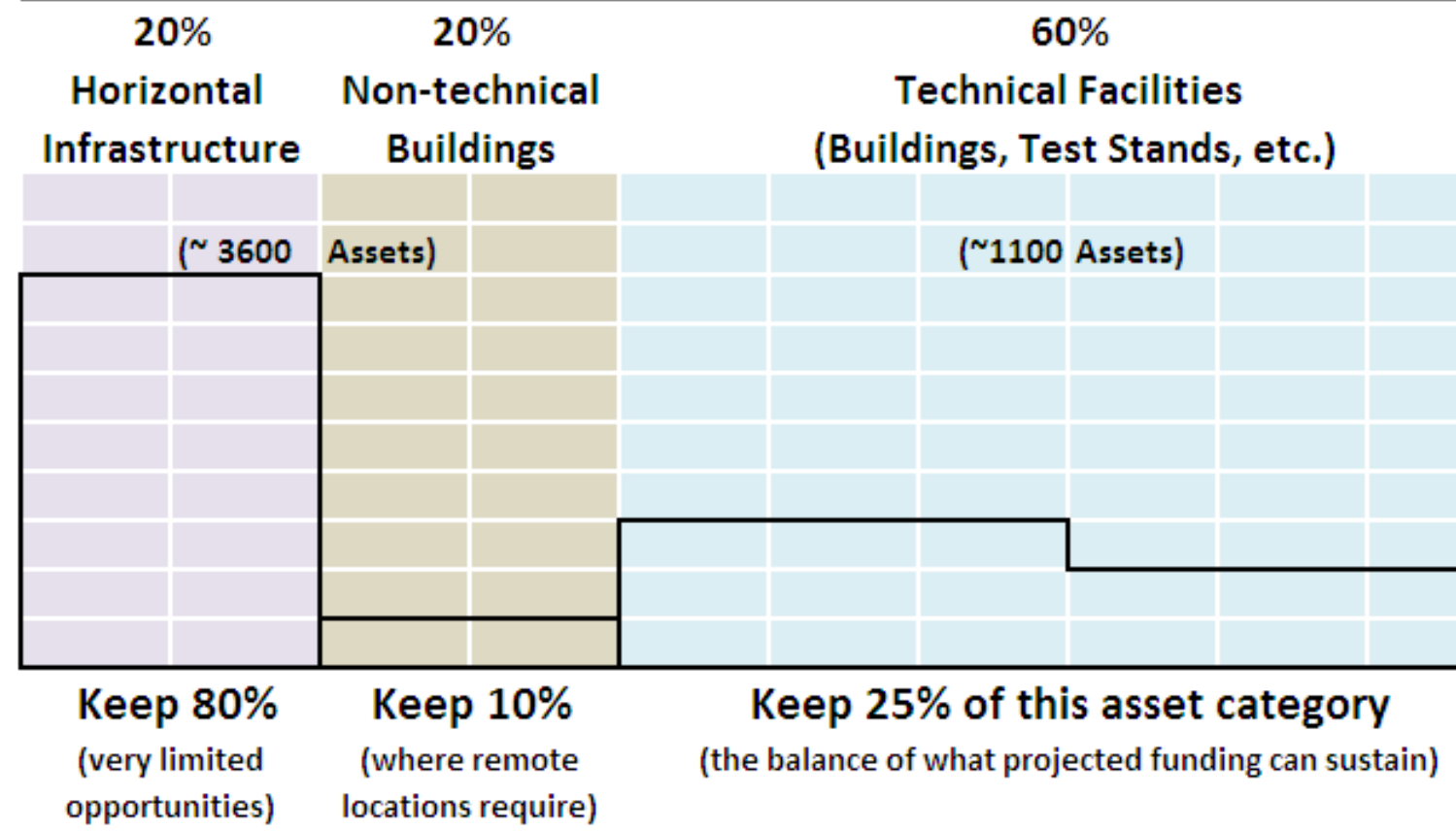

decisions. The finding was that RPMS data relating to these three elements was unreliable for evaluating NASA's real property assets due to inadequate processes to gather and update information at the Centers:

1. Utilization: many facilities were categorized as utilized, but were not.

2. Mission dependency: varying definitions of mission across the Centers, with a bias (85\% at the Centers visited by the IG team) found for facilities to be categorized as "mission dependent" or "mission critical".

3. Condition: tracking of physical condition generally performed by small teams under tight deadlines, resulting in cursory and inaccurate findings.

Thus, a need exists for the Centers to improve the data feeding the RPMS - data quality is also an important element of having good information upon which to base maintenance and investment prioritization decisions.

A number of process issues that can affect maintenance quality and efficiency are not addressed in this paper that, if done well, would be complementary to prioritizing needs to get the most out of available maintenance funding. These include:

- Producing robust requirements definition for new or upgraded assets that provide:

- Commonality of equipment across systems and subsystems (optimize at higher asset hierarchy levels to reduce the different types of equipment with similar function);

- Defined usage needs in advance of occupancy/use (service systems, communications, environment management, floor loading, physical space, people and equipment access, security, etc.);

- Proper assessment of existing asset condition for interfacing of new equipment;

- Defined maintenance needs;

- Defined (proper) operation of equipment;

- Defined reliability/availability.

- Accomplishing life cycle economic assessments for new or upgraded assets that define initial and annual costs and expected viable usage life, including: 
- Equipment life - defines future recapitalization needs;

- Periodic PM requirements and costs;

- Expected reactive maintenance costs based on manufacturer failure data and operational applications.

- Managing facilities/assets as a system across the Center (and the Agency):

- Common equipment (and documentation) within and across facilities;

- Goal of same look/touch/feel within and across facilities;

- Interfacing new and old infrastructure, sometimes with different loads/use put on older infrastructure;

- Process to vet procurement of research equipment (to ensure future maintenance needs are met.

As Dr. Whitlow noted in his briefing, there is much more work to do to determine what assets are to be retained and to what level of performance. It is also clear that improved maintenance processes that provide specific levels of support to assets are crucial to accomplishing current and future NASA work - whether to maintain recapitalized assets in top condition (nearly all proactive work) or to keep aging assets viable as missions, plans, and budgets evolve. Data used to prioritize work must be robust enough to address the issues cited in the August 2011 IG report. The approach documented herein consists of a review of current maintenance practices across NASA and the development of a future state (that could be evolved from the present state) that delivers services to provide a range of capability readiness based on available budget. The future state specifies services based on strategic and tactical mission alignment combined with the ability of a facility to deliver performance. This approach still requires difficult decisions since merely spreading available funding and cost reductions is just slow degradation to overall obsolescence and is thus not acceptable. This new approach will ensure the facilities with the strongest mission alignment have the ability to deliver.

\section{Current Maintenance Processes and Challenges}

The current maintenance process will be described based on NASA Procedural Requirement (NPR) 8831.2E, "Facilities Maintenance and Operations Management", with several specific examples taken from current practices at NASA Langley. NPR 8831.2E is summarized using four primary categories:

A. Foundational. This category includes the logistics, information (and information management), and processes associated with accomplishment and management of all maintenance at a Center.

B. Preventive maintenance. All activities associated with performing PM procedures, facility condition assessments and follow-up on findings, and predictive testing and inspection (PT\&I) and follow-up on findings.

C. Reactive maintenance. All activities associated with performing equipment repairs. This includes initial identification of a problem, initial response, and follow-up repairs.

D. Asset investments. Investments take a multi-year perspective, taking into account capability need dates and budgetary lead times, and include recapitalization planning and execution, improvement and modernization planning and execution, and asset divestment planning and execution.

\section{A. Foundational Logistics, Information, and Processes}

The scope and approach of the maintenance program is defined in an Annual Work Plan (AWP) that provides the types and quantities of maintenance to be performed and can include multiple funding sources. "A wellconceived and comprehensive AWP will clearly substantiate the need for good, strong, and well-articulated justification for requesting, managing, and properly allocating maintenance and repair funds for the responsible stewardship of NASA facilities." ${ }^{16}$ The AWP should serve as a guide for maintenance activities, ensuring that Center priorities are being addressed and moving the maintenance program toward a more proactive mode of operation. The AWP should be constructed to align with and support the Center Master Plan, which is the long-range, missionaligned vision for facilities and capabilities at the Center. Elements of the AWP are:

- Compilation of all maintenance and repair work to be accomplished during the year, including providing an allowance for unknown work that will arise.

- Funding requirements for the current year and for a five-year projection.

- Scope and funding organized into categories: PM, PT\&I, grounds care, programmed maintenance, repairs, trouble calls, replacement of obsolete items, service requests, central utility plant operations and maintenance, rehabilitation, modernization and repair, and construction and alteration. 
- Staffing requirements for both civil servants and contractors.

- Deferred maintenance history, deferred maintenance reduction (demolition) funds.

- Special programs: facility condition assessments, reliability centered maintenance, CMMS critical spares, 24/7 presence, electrical power monitoring, emergency operations support, and maintenance of fabrication technology equipment.

- Use of the Mission Dependency Index (MDI) to define buildings grouped by mission criticality.

- Overall facility conditions defined by building system category.

Specific scope and quantities of services are based on historical data and active management of future direction. It is likely that not all categories will be funded each year.

The allocation of scope and budget based on MDI score and current condition is a process implemented in recent years at some Centers. The process tries to meet maintenance needs in a prioritized manner, making needed repairs and accomplishing PM for all facilities except those with the lowest mission alignment and a select few with very low workloads (allowing deferral of maintenance until the capability is needed). MDI and current condition also support decisions to take capabilities to inactive status - including some that lead to abandonment and demolition, and as more Facility Condition Assessments (FCAs) are completed, condition assessment data quality will improve.

Each Center utilizes a computerized maintenance management system; even though software, structure, and information quality varies across the Centers, all NASA Centers and Component Facilities have recently reached a consensus in using Maximo ${ }^{\circ}$ as the common CMMS throughout the Agency. ${ }^{7}$ This standardization will streamline and simplify reporting, consolidate and centrally manage seat licenses, and reduce CMMS costs. A fully capable CMMS contains :

- The functions to manage facilities and equipment (facilities maintenance processes and procedures to be used in managing the facilities maintenance workload);

- Facility/equipment inventory (data files/modules containing a detailed inventory of all facilities and maintainable collateral equipment subject to the facilities maintenance management system);

- Work input, control, and scheduling (contains information on work requested by customers, work generated internally, and status as work proceeds from requirement identification to completion or request disapproval);

- Reliability centered maintenance (contains information on facilities and equipment criticality codes, maintenance requirements, and schedules);

- Correlation of maintenance data (benefits can be realized by correlation of various metrics, trends, and data from the PM, PT\&I, and other databases - the CMMS automates that correlation);

- Continuous inspection (information for the continuous inspection program);

- Facility/equipment history (summaries of the maintenance histories of the facilities and collateral equipment);

- Utilities services (detailed information on utilities consumption, distribution, use, metering, allocation to users, and cost);

- Assistance in formulating and administering contracts (information on contracts supporting the broad spectrum of facilities maintenance management as required by the Contracting Officer, Contracting Officer's Technical Representative (COTR), and Quality Assurance Evaluators (QAE));

- Budgets and perform cost analyses (to obtain and track resources, provide tools and techniques to account for resources, and to perform in-depth analyses of requirements)

- Reports and metrics, job estimating, tools and materials data files;

- Environmental information (permits, licenses, the history of violations and citations, potential hazards, environmental compliance and related actions underway, and tracking of work or materials of special environmental interest);

- Space management/planning (user name and user data for each facility, space within the facility, or other managed asset);

- Facility graphic documentation and configuration control; and

- Other database functions. 
At least one NASA Center uses a process to divide the work based on asset ownership using a determination of whether a piece of equipment is deemed institutional (Center infrastructure, typically serving multiple users) or research (used by a particular group for research purposes). This parses the funding required, pushing research equipment repairs onto research budgets. This process doesn't really address the situation of considering life cycle costs when research equipment is procured and it is also difficult to enforce, with significant overlap of the two equipment types. For the purposes of this paper, this discriminator will not be used, instead addressing all equipment/assets as government owned.

\section{$\underline{\text { Real Property Measurements }}$}

"Mission dependency identifies the relative importance of real property assets in relation to NASA's mission. NASA collaborated with the Navy and Coast Guard to develop a method for measuring mission dependency in 2001 and began collecting data in 2004. Mission dependency data is intended to help NASA managers better manage risks to programs and guide investment and divestiture decisions. NASA Centers are required to assess and update mission dependency scores for all assets every three years. Asset assessments are based on the responses to two questions related to the asset's impact on mission:

"How long could the functions supported by your infrastructure be stopped without adverse impact to the mission?

"If your facility was not functional, could you continue performing your mission by using another facility or by setting up temporary facilities?

"Each asset is given a mission dependency score on a scale of 1 to 100. Assets with mission dependency scores of 71 to 100 are considered "Mission Critical," 10 to 70 are "Mission Dependent," and 0 to 9 are "Not Mission Dependent." "Mission Critical" assets are those assets that would compromise the Agency's mission if unavailable. Assets that are "Not Mission Dependent" would have no effect on the Agency's mission if unavailable. "Mission Dependent" assets are those assets that are neither "Mission Critical" nor "Not Mission Dependent."

"Condition data provide information on the physical condition of the Agency's real property assets at a specific point in time. To measure the condition of each asset, NASA . . perform[s] annual condition assessment surveys of all facilities. For each asset ... nine major systems [are rated]: structure; exterior; roof; heating, ventilation, and air conditioning; electrical; plumbing; conveyance systems (e.g., elevators); interior; and equipment. NASA calculates a condition index score using a five-point scale for each asset using the contractor-provided ratings. According to the NASA Real Property Asset Management Plan, assets rated as a five are newer facilities with little or no repairs needed, assets rated lower than three are considered in poor condition, and any asset rated as a one should be condemned.

"Facilities may be designated in the RPMS as (1) Overutilized, (2) Utilized, (3) Underutilized, or (4) Not Utilized. NASA regulations require Centers to identify utilization rates for all real property assets annually. To determine utilization, officials review each asset to determine a percentage of space used in comparison with the total space available or a usage level based on a comparison with the number of days the facility is available. Based on a comparison of each asset's usage with NASA and Federal thresholds, Center officials record the corresponding utilization rate in the RPMS. NASA guidance requires facility usage rates to exceed 50 percent."

A significant issue with this process is that the current MDI criteria provide an evaluation of institutional equipment and systems and don't necessarily account for alignment of technical assets with mission requirements for a large portion of NASA facilities. This will be developed in Section IV of this paper.

\section{B. Preventive Maintenance}

The PM program consists of three major elements:

- PM procedures, findings, and data management;

- PT\&I; and

- FCAs. 
The goal of the PM program is to sustain equipment life cycles, while accomplishing the maintenance in an efficient manner. Efficiency relates to accomplishing work prior to significant degradation (typically aligned with manufacturer suggested maintenance practices) at the lowest possible cost. "PM consists of regularly scheduled inspection, adjustments, cleaning, lubrication, parts replacement, calibration, and repair of components and equipment. PM schedules periodic inspection and maintenance at predefined intervals in an attempt to reduce equipment failures for susceptible equipment. As equipment ages, the frequency and number of checkpoints may need to be evaluated ... Traditional PM is keyed to failure rates and times between failures. It assumes that these variables can be determined statistically. Therefore a part due for failure can be replaced before it fails." ${ }^{10}$ Thus, programs are evolving to improve efficiencies by moving from work on a timed basis for individual components to groupings of equipment (promoting downtime coordination with operations) and moving toward a condition-based approach to scheduling work.

PM procedures are flagged in advance (typically sixty to ninety days) to both the maintenance coordinator at the respective facility location of the equipment and the functional maintenance planner. PM tasks vary widely on potential impact to operations, ranging from very low impact (accomplish in parallel with operations or in odd bits of time that fall out of the schedule) to major impact (requiring extensive down and sometimes significant system disassembly). An integrated schedule is used by Centers to minimize disruption of operations while providing sufficient time to accomplish maintenance work.

Another element of PM is identification of deficiencies in equipment that require repairs during the PM process. These "PM finds" are a form of corrective maintenance, but are important in that functionality often hasn't been impaired (at least to the point of noticing), so the problem can be fixed without further collateral damage - typically these repairs are prioritized at least one level higher than other like repairs. It also provides an opportunity to examine other similar equipment for PM application.

"Predictive testing and inspection (PT\&I), also known as predictive maintenance or condition monitoring, uses primarily nonintrusive testing techniques, visual inspection, and performance data to assess machinery condition. It replaces arbitrarily time maintenance tasks with maintenance that is scheduled only when warranted by equipment condition. . . . Collected PT\&I data is used for trend analysis, pattern recognition, data comparison, tests against limits and ranges, correlation of multiple technologies, and statistical process analysis to determine the condition of the equipment and to identify the precursors of failure." ${ }^{11}$ Elements of PT\&I technologies include vibration analysis, lubricant and wear particle analysis, thermal imaging and temperature measurement, passive (airborne) ultrasonics, electrical testing and motor current analysis, flow measurement and leak detection, valve operation, corrosion monitoring, process parameters, and visual observations.

The FCA process consists of: 1) baseline data, 2) inspection team and inspection, and 3) analysis and reporting. ${ }^{12}$ Baselining the data consists of preparing for the inspection by determining the assets that need to be inspected, the data that will be collected, the types of standards and rating schemes that are to be applied, and the method of collecting and storing the data (paper or electronic forms, log sheets or computer databases). Inspection team and inspection consists of determining who will perform the audits (number of personnel and skill sets, self inspection or outsourced) and conducting the physical inspections. Analysis and reporting encompasses analysis of the FCA data and reporting of results. ${ }^{13}$ An important element of the final report is the identification of safety critical items that will need immediate correction. FCAs occur on a cycle, dependent on scope of facilities, expected changes in facility conditions, and budget to accomplish FCAs.

\section{Reactive Maintenance}

Reactive maintenance is maintenance required to fix something as a result of an unanticipated deficiency in performance. If resources are not constrained, PM is robust, minimizing reactive maintenance. Unfortunately, this is not the situation at the NASA Centers. Reactive maintenance often costs more than PM - failures also can cause collateral damage and unplanned downtime, further driving up costs and impacts to products. Based on failure rate data and levels of maintenance associated with equipment reliability, a certain amount of reactive maintenance is expected and a certain amount of funding is budgeted. Typically a deficiency is identified and a trouble call (TC) is made that will result in designated personnel initially addressing the deficiency. Often, some form of repair is required; simple repairs are often accomplished immediately. Again the following is a summary of the nominal process described in NASA NPR 8831.2E. 
$\underline{\text { Initial Problem }}$

Any problem, typically associated with some deficiency in performance, can be identified by anyone at a Center. A TC or work order is initiated, with mobilization and timeliness of response based on criticality of the situation. The minimum initial response is to secure the problem, make the area safe, and clean up as required. At this point, subsequent actions become repairs.

$\underline{\text { Repairs }}$

For some straightforward repairs, the TC responders may fix the problem with on-hand materials; otherwise some form of work request is initiated. There are six levels of priority as shown in the sample priority list from NPR 8831.2E (Table 1). When a repair request is initiated, it is assessed for priority (based on criteria established at each Center) and response is based on that priority. This also provides a sorting function for work needs and, when combined with other factors such as mission alignment and facility condition or performance, forms a sort of cut list for work to be performed when budgets are limited.

\section{Asset Investment}

Asset investment is the process of recapitalizing existing assets/capabilities for sustainment (buying back design life) and funding improved capabilities to better meet current needs and/or be ready to meet future needs when required. It was shown in Section II that infrastructure investment needs just for sustainment, not including improvements, far exceeds investment funding availability. Investment funding flows to Centers in multiple ways, including Construction of Facilities funds allocated from NASA Headquarters (HQ), Center Management and Operation funds allocated to the Centers from NASA HQ and then by the Centers, Aeronautics Test Program (in the Aeronautics Mission Research Directorate), and from individual programs from across mission directorates. There exist various means of prioritizing investment needs (which investments get funded and when) across the Centers, within NASA HQ, and within the funding sources; it is beyond the scope of this paper to describe these processes further beyond noting that they exist. The pertinence is that investments directly affect the maintenance required and the information used to prioritize maintenance also supports decisions regarding which investments receive approval and funding. It should also be noted that investment work in existing facilities often require significant downtime, so scheduling is integrated with ongoing operations and maintenance work.

\begin{tabular}{|c|c|c|}
\hline \multicolumn{3}{|r|}{ General Maintenance Work Priority System } \\
\hline Number & Description & Criteria Based on Consequences of Equipment/System Failure \\
\hline 1 & Emergency & $\begin{array}{l}\text { Safety of life or property threatened; immediate mission impact; loss of utilities. Begin immediately; divert } \\
\text { resources as necessary; overtime may be authorized. }\end{array}$ \\
\hline 2 & Urgent & $\begin{array}{l}\text { Maintenance or repair work required for continued facility operation; should be completed to ensure } \\
\text { continuous operation of the facility and to restore healthful environment. Not a life-threatening emergency. } \\
\text { Respond upon completion of current work but within a specified period of time (specified by local Center, such } \\
\text { as same day or within } 4 \text { hours). }\end{array}$ \\
\hline 3 & Priority & $\begin{array}{l}\text { Work that is to support the mission on a priority basis or to meet project deadlines. Complete in order of } \\
\text { receipt with mission work taking priority. }\end{array}$ \\
\hline 4 & Routine & $\begin{array}{l}\text { The facilities maintenance work can be scheduled routinely within the capability of the facilities maintenance } \\
\text { organization. Facilities work is subject to availability of resources and may be consolidated by facility or zone } \\
\text { or as directed to obtain efficiency of operation. }\end{array}$ \\
\hline 5 & Discretionary & $\begin{array}{l}\text { Work that is desired but not essential to protect, preserve, or restore facilities and equipment; typically, new } \\
\text { work that is not tied to a specific mission milestone. Work that is desired but not essential to protect, preserve, } \\
\text { or restore facilities and equipment; typically, new work that is not tied to a specific mission milestone. }\end{array}$ \\
\hline 6 & Deferred & $\begin{array}{l}\text { Work that may be safely, operationally, and economically postponed. The work should be done, but cannot be } \\
\text { scheduled because of higher priority work, funds shortage, work site access, or conditions outside the control } \\
\text { of the maintenance organization. The work may be reclassified if conditions permit or included in the DM. }\end{array}$ \\
\hline
\end{tabular}

Table 1. Maintenance Work Priority. 


\section{Asset Management in a Budget Constrained Environment}

The current process of using the MDI for mission alignment, findings/ratings from FCAs to determine condition, and current utilization to value a facility within NASA may provide inadequate information to decision-makers due to the tactical (and, possibly, incomplete) nature of the data. An improved approach utilizes a process developed and implemented by the United States Coast Guard for the Shore Facility Capital Asset Management initiative. ${ }^{14}$ The tools and processes described in $8831.2 \mathrm{E}$ are still used to accomplish maintenance effectively and efficiently, but the future state process adds strategic alignment with mission and facility functional performance to provide a more balanced indicator of facility worth and to better guide maintenance, investments, and divestiture decisions. The maintenance and investment needs of a facility can be prioritized against other Center needs based on mission alignment and facility performance, using an established process known as financial (or management) performance; as illustrated in Figure 4 and with each element discussed next.

\section{A. Mission Alignment}

Every facility at each Center can be aligned with NASA missions, with each mission element tying back to NASA Strategic Goals and Outcomes ${ }^{15}$ (2011 strategic goals included as Appendix 1). NASA is organized by mission directorates, and the projects within each directorate are working the current missions for the Agency. Since many of these projects relate to near-term purposes, needs of longer-term or future missions may not be adequately considered for facility sustainment priorities. Thus, strategic alignment to core NASA missions must also be overtly considered, as illustrated in Figure 5.

NASA's six strategic goals, each with stated desired outcomes and associated metrics are, by design, at a high level of definition. Specific Center products/output must be related to one or more of the desired outcomes. This then allows the mapping of capabilities of each Center product area with each strategic goal outcome.

The MDI is a measure of current readiness to support multiple missions. A US Navy briefing will be used to illustrate one version of the $\mathrm{MDI}^{16}$ (and Dempsey ${ }^{17}$ states that variation of this are in use by the Coast Guard, Navy, NASA and the Army Corps).

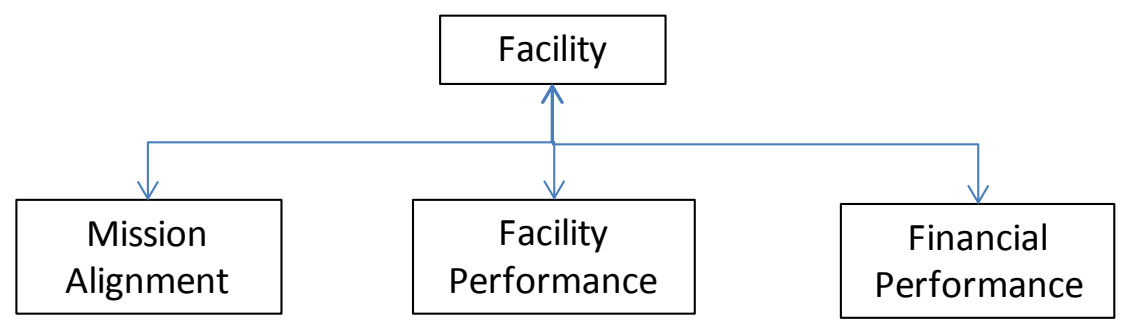

Facility: A collection of systems that provides a function for operation or a capability. A facility can be a combination of one or more buildings or one or more rooms within a building. Each function includes designed reliability and production performance. For NASA, examples include: fundamental operation of a wind tunnel, research lab operation, and office building operation.

Mission Alignment: The relationship facilities have to achieving the organization's desired mission outcomes Facility Performance: How well a facility is performing its intended purpose (independent of the facility's relationship to mission)

Financial Performance: A well established structure that evaluates competing priorities in a resourceconstrained environment. Integrated with the other two areas, focuses decision-making and methodical evaluation of risks to maximize facility performance and achieve desired organizational mission outcomes

Figure 4. A Model for Facility and Center Asset Management. 
Figure 5. Mission Alignment Elements.

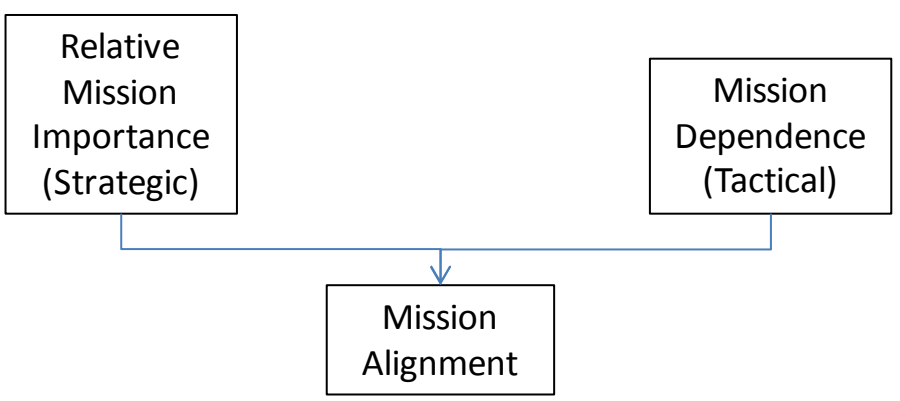

Relative Mission Importance (RMI): Considers relative importance of each of the NASA mission areas applied to facilities at a Center. Additional consideration is given to facilities that support US National missions outside of NASA mission areas. Findings can be tabulated in an index (RMII).

Mission Dependence (MD): Describes the relative importance of a facility in terms of mission criticality. Determination of a facility's readiness to perform multiple missions in support of operational needs of individual efforts/tasks/projects in the form of an index (MDI) that applies probability and severity risk assessments in terms of interruptability and replacability.

Mission Alignment: Combine RMII and MDI to determine facility importance scores.

Problem: How do we clarify the linkage between facilities and mission?

Solution: Operational Risk Management (make the right decisions at the right level) via the deployment of a risk based metric that describes the relative importance of Naval shore infrastructure in terms of mission criticality.

If a facility is destroyed/closed or non-functional, what are the mission impacts or consequences?

1. Intradependency, $\mathrm{MDI}_{\mathrm{w}}$ (within mission - infrastructure controlled by the mission)

a. (Interruptability) How long could the functions supported by the facility be stopped without adverse impact to your mission? (timescale answer)

b. (Replaceability) If the facility were not functional, could you continue performing your mission by using another facility, or by setting up temporary facilities? (answer: possible, difficult, impossible)

2. Interdependency, $\mathrm{MDI}_{\mathrm{b}}$ (between missions or facility owners - infrastructure not controlled by the activity)

a. (Interruptability) How long could the services provided by (named organization) be interrupted before impacting your mission readiness? (timescale answer)

b. (Replaceability) How difficult would it be to replace or replicate the services provided by (named organization) with another provider from any source? (answer: possible, difficult, impossible)

Source of information: Ask the operator - Rely on the prudence, experience, judgment, intuition and situational awareness of leaders directly involved.

Scoring: A risk assessment matrix with a range of one to six is used to score a facility for $\mathrm{MDI}_{\mathrm{w}}$ and $\mathrm{MDI}_{\mathrm{b}}$. An algorithm is used that weights the scoring for each as well as the number of missions supported.

From the NASA MDI User Guide ${ }^{18}$ :

"The MDI was tested in 2003 at NASA Wallops Flight Center, and fully implemented at all NASA Centers in 2005 and 2006. MDI identifies the relative importance of NASA facilities in terms of mission requirements and can be used by NASA facilities managers to make strategic decisions regarding the NASA facility inventory. . . 
"MDI also takes into account mission "Intra" dependencies (those that reside within an organizational unit at a NASA Center) and mission "Inter" dependencies (those that reside between organizational units at a NASA Center). It does this through a structured interview process that captures the "experience, judgment, intuition and situational awareness of leaders having authority over operational and facility decisions." The product of the interviews is a quantitative score normalized over a scale from 0 to 100, with higher scores representing higher mission dependencies or mission critical facilities."

"NASA MDI derives from, but differs from Navy MDI and Coast Guard MDI by using a maintenance perspective rather than an operational/military perspective. The majority of NASA Centers perform Research and Development $(R \& D)$ and do not have operational missions. Relocation, replacement and repair, measured by cost, were found to be more accurate and relevant measures at R\&D Centers. Repairability was added to NASA MDI to better represent maintenance, one-of-a-kind infrastructure, and equipment which has no equivalent elsewhere. Repair sometimes is the only option."

"NASA has operational facilities: e.g. mission control and rocket launch \& recovery. Availability, capability and difficulty are most important factors for these facilities, and often have redundant or backup capability. They are more military like in their missions. Availability, capability, and difficulty were found to be the most accurate and relevant measures for operational Centers associated with launching and controlling spacecraft."

"NASA MDI decomposes infrastructure into multiple levels:

- Facility - Building

- Facility Component - Room/Space

- System - Service

- Equipment - Fixed/Large/Unique/Costly

- Linear Structure - Road/Rail/Pipeline/Fence/Pavement/Bridge

- Network Facilities - Utility/Network"

Thus, MDI scores should be available across NASA Centers, though for the purposes of this model, scoring will need to be normalized (perhaps rolled-up) at the defined facility levels. However, this model can be applied at whatever level of infrastructure decomposition is desired by Center management. This index provides a numerical score between one and one hundred to create a prioritized rating of facilities across a Center based on alignment with current mission elements.

The Relative Mission Importance Index (RMII) is a measure of facility alignment with NASA strategic missions, as defined in the NASA Strategic Plan goals and outcomes (Appendix 1). This is accomplished by:

1. Develop, if not already in hand, an alignment of specific Center capabilities with the specific strategic goal outcomes. Some capabilities will align (probably with different strengths) with multiple outcomes.

2. Using a Center facility list, match each individual facility to the capabilities directly supported. This provides linkage to the strategic outcomes.

3. Assess the RMII for each facility by rating for importance on a one to four scale of support to each identified strategic outcome link:

1 - None (no impact at loss of facility)

2 - Little to some (some possible impact if facility is unavailable, but with other options)

3 - Important (likely impact if facility is unavailable with possible workarounds)

4 - Critical (facility is critical to product development or implementation, no viable workarounds)

Each facility will likely support multiple products across goals and outcomes, so the highest level of importance linked to a particular outcome should be used for scoring purposes. This provides a prioritized listing of facilities based on strategic importance. As this process matures, it is expected that the mission area owners will need to concur with the assessment.

An additional consideration is facility alignment with National mission needs. Since the early NACA (National Advisory Council for Aeronautics) days, NACA and then NASA facilities have provided extensive support to 
mission needs of other government agencies, US industry, and academia. NASA leadership can choose one of two paths relating to these mission needs: 1) adjust a facility score higher based on specific National need (with risk that NASA may have to cover the costs of facility sustainment for other's needs), or 2) flag to the mission need owner that a critical facility may be at risk and work together to address the situation.

For this new process, the strategic RMII score and more tactical MDI score are combined for each facility to provide an overall assessment of that facility's importance to the agency. This combined approach is crucial as asset sustainment budgets are tightened and the agency seeks to reduce infrastructure:

- Identifies facilities that will be needed, allowing smart sustainment actions today (such as performing a planned standdown with knowledge capture, records management, and defined levels of low maintenance) to keep them available for future needs.

- Provides advocacy information for sustainment and investment funding from stakeholders.

- Provide assurance that risk to mission is low for divestment of particular facilities.

The alignment to mission can now be determined for both near-term (current, tactical) needs and for long-term (future, strategic) needs by producing one mission alignment score. The score is determined by multiplying the RMII score and the MDI score. Adjustment up can be made for alignment with National needs by facility owners by adding points to the mission alignment score. These scores can then be placed into mission alignment quintiles:

Level 5: $320-400$ (Very high mission alignment)

Level 4: $240-319$ (High mission alignment)

Level 3: $160-239$ (Moderate mission alignment)

Level 2: $80-159$ (Low mission alignment)

Level 1: <80 (No mission alignment)

In summary:

1. Utilize existing MDI information to list each "facility" at a Center in order of score,

2. Define the RMII for each facility.

3. Define additional National (non-NASA) mission alignments and associated importance to meeting that mission. Center management can utilize this information to adjust up the mission alignment score.

4. Calculate a mission alignment score.

\section{B. Facility Performance}

Some NASA Centers are currently performing facility condition assessments (FCAs) to determine the current needs of each facility and is used to validate the asset management plans (annual and five year work plans, Center Master Plan) and processes (deferred maintenance, replacement of obsolete items) of the Center. But the FCAs are only a measure of condition. Additional measures (functionality, availability, utilization) can provide a better understanding of a facility's readiness to meet mission needs. The new process adds a measure of functionality to the FCA information.

The FCA process, typical to current use by NASA, provides a snapshot of condition and tends to be biased toward institutional asset content (eight of nine rated building elements are institutional in nature). ${ }^{19}$ But many of NASA's facilities are experimental test and operations oriented, with unique, high cost equipment that adds complexity to maintenance requirements. For selected facilities with this situation, NASA has accomplished additional capability assessments that define deficiencies by scoring specific system ability to meet needs ${ }^{20}$. Where this information is available, it can be averaged for a specific capability with the institutional FCA findings (or a weighted average can be used, at the discretion of Center management).

Utilization relates to usage of the facility, in terms of required (actual, planned or both) amount of operation over a given period. Usage includes all activities occurring in the facility that pertain to its intended purpose. Most corrective maintenance and use-based preventive maintenance needs are driven by the type (some usage is harder on infrastructure than others) and amount of usage. Utilization is also a qualifier that supports tailoring of a maintenance program by flexing operations and/or taking advantage of underutilization to gain access to assets for 
maintenance. Facility capabilities will be needed at certain times, but often not all the time, allowing phasing and grouping of work. Tailoring for some managers, especially for facilities with high demand, means accomplishing operations at the expense of maintenance; ultimately this will result in decreased reliability and a corresponding increase in down times (and corrective maintenance). But tailoring also means PMs and repairs can be accomplished when needed, not on a calendar basis.

Utilization as a singular discriminator for prioritizing maintenance can be misleading, primarily for facilities with specialty capabilities that are only occasionally required. Certainly use-related maintenance can be timed to need, stretching out periods between maintenance. But utilization does not necessarily correlate with importance capability readiness may be more important. For the purpose of this prioritization model, utilization will be left for use by maintenance planners/schedulers and not used as a discriminator for prioritization.

Availability is the readiness of the facility to provide intended services at any given time, whether it is actually occurring or not. It is a function both of system reliability and designed capacity. Designed capacity is the current planned availability; capacity can be constrained below original facility design levels by constraining resources required to operate (such as staffing or electrical power).

Functionality is the ability of a facility to meet its intended purpose in terms of mission support (operations). It also includes logistical readiness in all the areas that must be addressed, in additional to readiness mechanically and electrically, prior to operating the facility. These are:

- Safety requirements and best practices

- Legal (code compliance)

- Environmental requirements and best practices

- Energy efficiency requirements and best practices

- Asset stewardship (the needs of the facility are understood and addressed)

- Staff readiness (knowledge, training, certification, demonstrated ability to deliver)

- Product quality (documented processes, data traceable to standards, defect measurement and tracking)

- Operation quality (proper operation of facility equipment, operation design, appropriate application of capabilities to address test needs)

Each facility can be assessed in terms of functionality in its overall ability to deliver nominal operations and in terms of logistical readiness. A suggested process is for facility stewards (facility coordinators, facility safety heads, and facility managers, as applicable) to make the initial assessment using a five-point scale:

Level 5: Fully functional (high availability; all capabilities functional to design levels)

Level 4: Functional with some deficiencies (mostly available, with occasional significant downtimes; all/most capabilities fully functional)

Level 3: Functional with significant deficiencies (significant downtime is not unusual, some capabilities either not functional or fully operable)

Level 2: Partially functional with significant deficiencies (significantly to mostly down, capabilities limited)

Level 1: Not functional (until deficiencies addressed)

This scoring can be made less subjective by using operational data (system reliability, MTBF, MTTR, corrective maintenance trending, customer satisfaction survey data on facility performance) to develop criteria for level of functionality for types of facilities. For this paper, for the purposes of wide model application (and to keep it simple), the subjective scoring will be used. An obvious caveat is to have cross-Center maintenance management to review scoring for consistency will their overall knowledge of conditions - there likely will have to be some pushback on facility stewards trying to game the results.

Now the data from the FCAs is required to provide a measure of both current condition (and deficiencies) and actual facility ability to deliver services. Each FCA is scored for a particular facility using a five-point scale, typically like this: 
Level 5: Excellent, like new condition

Level 4: Good, routine maintenance

Level 3: Fair, minor repairs required

Level 2: Poor, significant repairs required

Level 1: Bad, replacement required

For technical (research/operational) facilities where additional equipment condition assessment information is available, the condition assessments should be combined to define levels. The combination process is left to Center management, but likely should use a weighting process based on criteria such as replacement value and criticality to the intended function of the facility.

These scores can be combined to provide an overall facility performance score by multiplying the FCA score and the functionality score. The result is a facility performance score ranging from one to 25 , with 25 being very high level of performance:

Level 5: $20.1-25$

Level 4: $15.1-20$

Level 3: $10.1-15$

Level 2: $5.1-10$

Level 1: $0-5$

In summary:

1. Assess each facility for functionality level.

2. Utilize existing FCA data to list each facility at a Center in order of score.

a. If additional equipment condition information is available, combine this with the FCA results to provide an improved score.

3. Combine the functional score and condition score for each facility to produce an ordered list of facility performance scores.

\section{Financial (Management) Performance}

Management performance addresses the processes associated with asset stewardship and integration of operations, maintenance, and capital investments (Figure 6). During times of high workload to meet critical needs, some will push for operation at the expense of maintenance, but it can be argued that maintenance is even more critical during those times. Often, a customer has a critical need to use a facility to address a product problem/issue, so schedules must be met while managing the tension between operation and performing maintenance. Neglecting maintenance will eventually cause increased failures with subsequent downtime and added repair costs. Asset management with a long-term view includes capital investments to sustain existing capabilities and to fund improvements to meet new needs. These investments typically require significant capability downtimes, so must be scheduled in advance and usually held to the planned downtime dates. Thus the management approach must be balanced between these needs, structured to support asset health and performance and flexible to meet often changing operational requirements.

Maintenance planning requires initially an understanding of operational needs, both near- and long-term, related to expected asset usage, schedules and shifts, critical needs/priorities, and expected challenges. Operational needs can be produced in formal plans with periodic updates, but at a minimum must be captured in some form of an integrated schedule that allocates time to specific efforts. The schedule should include likelihood of occurrence for each effort, to support decisions regarding priorities and management of changes. In this paper, scheduling is accomplished typically at the facility level, though can address operation of specific capabilities (especially those that are used infrequently and/or require special or additional resources to operate).

Investment, or recapitalization and improvement, management is mostly beyond the scope of this paper's focus on management and sustainment of existing assets. Recapitalization is a crucial element of sustaining capabilities, whether repairing by replacing (as noted earlier in the Whitlow briefing) or selective replacement of key components in systems; this investment element can be considered major maintenance and repair. The other investment element is upgrading capabilities to meet future expected needs - these investments are often program 
Figure 6. Management Performance.

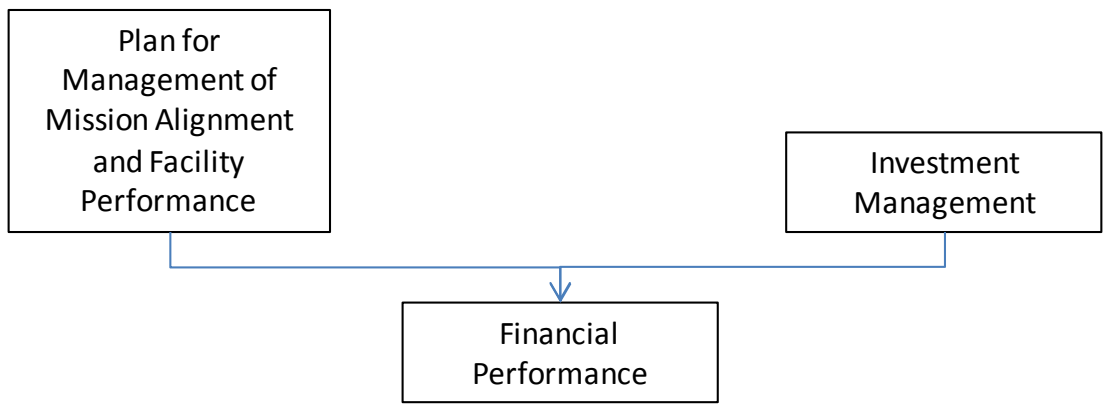

Plan for Management of Mission Alignment and Facility Performance: Integrated coordination and management of mission alignment and facility performance with financial management in a resource constrained environment.

Investment Management: Management of recapitalization and improvement and modernization projects required to provide future facility performance to meet future missions. Requires structured multi-year planning (need identification and prioritization process), funding identification and allocation process (with advocacy and justifications), facility downtime integration into operations schedules, and tracking of changing needs and facility readiness over time.

Figure 6. Management Performance.

driven but should be part of a comprehensive planning effort aligned with the strategic direction of each Center to meet mission needs. In summary, investment management should include three key elements:

- Multi-year recapitalization planning and execution.

- Multi-year improvement and modernization planning and execution.

- Multi-year divestment planning and execution.

Foundational

A maintenance plan, similar to that discussed in section II and specified in NPR 8831.2E, should be prepared to address all expected maintenance over a specified timeframe. It should address needs of all asset types, whether institutional, research, operations, or other forms of assets and regardless of funding sources. The responsibility for maintenance costs has varied over the years as business models, organizations, and funding sources and quantities have changed; it can be a source of contention based on who has primary stewardship of equipment. Each NASA Center allocates funding to organizations, though the funding is often to be used only for specific purposes with specific limitations defined. Additional funding flows across organizations from programs, sometimes involving the acquisition and maintenance of task-specific equipment. In some cases, equipment is purchased with inadequate consideration of life cycle costs, adding to maintenance needs without associated funding/resources. The maintenance plan should address all maintenance needs with identification of associated funding. It should also explain the prioritization process and identify unfunded needs. Ultimately, accomplishment of the maintenance plan determines current and vectored future asset performance.

The purpose of facility maintenance and capital investments is to provide specific functional capabilities in support of NASA missions. Use of the facilities to produce capability output is why the facility exists. Yet, the culture cannot be "operation always has priority"; the approach must be balanced between operations and maintenance/investments or eventually the facility performance will degrade well ahead of design projections. Maintenance planning requires an understanding of near- and long-term operational needs related to expected operations tempo (facility usage durations and cycles), schedules and shifts, critical needs/priorities, and expected 
challenges. Preferably this would be provided by a formal operations plan for each facility, developed within the context of the overall Center Master Plan. The Center organization producing operations plans may vary based on facility purpose; one set of grouped facilities might be institutional infrastructure (such as office buildings), linking infrastructure (such as electrical and power distribution), and research/test/production facilities (such wind tunnels, launch complexes, laboratories). This is at the discretion of NASA Center management, though it is important for responsibilities to be defined. Combined operations, maintenance, and investment work affecting the readiness of a facility must be captured in some form of an integrated schedule that allocates time to specific efforts. Scheduling "granularity" is often accomplished at the facility level (though operation of specific or unusual capabilities may sometime be included) and integrated across a Center.

The ideal future state could be a robust implementation of the elements of the AWP and information in the CMMS described in section II.A. Some key challenges to robust implementation are described below:

- Enterprise asset management is embraced and operational.

The Center utilizes a common asset hierarchy and system nomenclature, supporting grouping (in the CMMS) of asset items by functional systems and subsystems. The challenge comes from islands of uniquely developed asset groupings (geographical, buildings, facilities, purposes) over the decades within and across Centers (and sometimes not entered into the CMMS).

- Asset data is collected in a usable database.

Asset information management historically has lacked consistency (information collected, format, units, validation, different/local lists and databases, lack of asset relationships, more) and content (incomplete/inadequate specific asset information, both manufacturer specifications/callouts and historical data).

- Operational data is tied to assets in the same database

This is information resulting from the use of assets, such as operational times/durations, cycles, downtimes with causes identified, more). This information will be used to improve maintenance processes but targeting equipment with the greatest impact to operations and to improvements to operational processes (related to proper operation of equipment).

- Facilities are prioritized to mission and ability to perform

Provides a reasoned measurement of alignment of each facility with NASA (and, potentially, National) missions and a reasoned measurement of each facility's ability to perform (deliver on its intended purpose). This information will be used to help with prioritizing maintenance and investments across facilities at a Center. The use of the MDI and accomplishment of FCAs is used by Centers, though application, quality, and use of the information are somewhat sporadic.

Facility importance to NASA, with importance relative to National needs considered, is defined by combining the mission alignment index and the facility performance index, shown in Figure 7. The combination produces five graduated categories for criticality of need, shown in Figure 8. Both the mission alignment index and the facility performance index are scaled from a low of one to a high of five and the facility performance index is scaled similarly. Thus the facilities with high scores in both categories are the most critical to NASA and the highest priority for maintenance and capability-sustaining capital investments. When plotted as a grid, zones can be defined for five levels of priority:

5: High mission alignment and facility performance; accomplish full proactive (preventive) maintenance and full reactive (repairs) maintenance (may be timed to need).

4: High facility performance but low mission alignment; accomplish sustaining preventive maintenance (selected PMs are deferred and/or periods stretched) and defer least important repairs (not impacting core capabilities).

3: The facility performance is deficient, unable to meet some or all mission needs (required recapitalization first); accomplish minimum sustaining preventive maintenance and repairs until recapitalized or divested. 
2: Low mission alignment; accomplish minimum sustaining preventive maintenance and repairs until mission alignment increases or facility is divested or put into inactive (standby or mothball) status.

1: Low mission alignment and low facility performance; abandon facility and divest. 
Figure 7. Integrating Mission Alignment and Facility Performance.
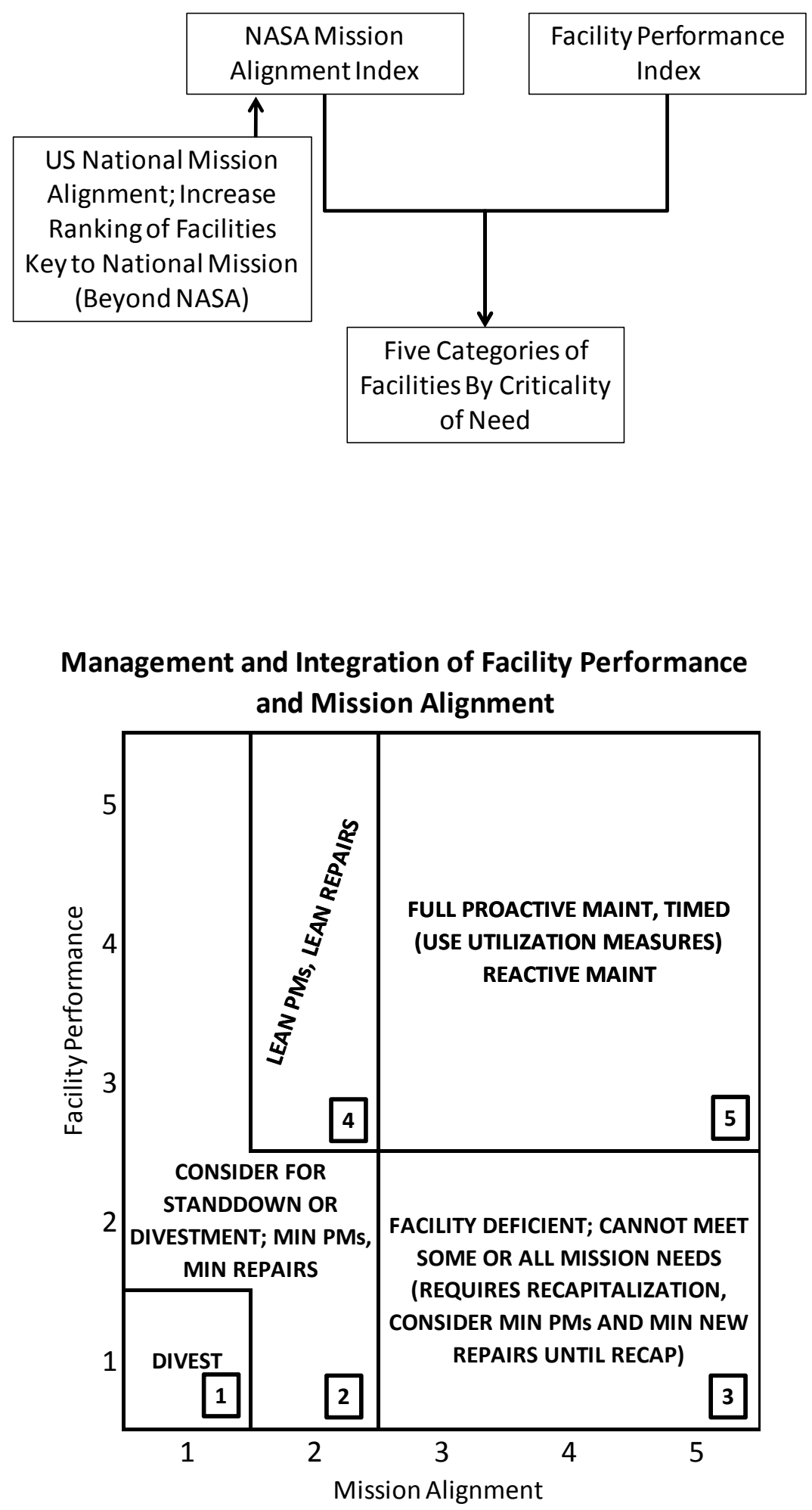

Figure 8. Combined Indexes. 
It should be noted that the scaling of the priority levels is arbitrary, based on the likelihood that even a facility with some deficiencies is important to level three and up mission needs, thus producing a level five. However, Center management should define scaling based on their assessment and available budgets.

Proactive and reactive maintenance work is accomplished based on criticality of need for a particular facility to NASA and the budget - the more limited the budget, the less work that can be accomplished on increasing higher priority needs. Facilities are organized in the five levels of criticality, the budget and Center management determines how much work below level five gets accomplished. The first step is to fund level five needs, then as much of level four as is available, leaving some amount to accomplish sustaining work on levels three and two. The priority of work for levels four, three, and two should be determined by needs most critical to the Center. Larger required repairs may utilize some form of tactical engineering to provide a rough order of magnitude scope definition and associated cost and schedule estimates to assist with management decisions. Figure 9 provides a notional table showing priority-related funding of maintenance work.

It must be noted that any reductions in preventive maintenance for a facility are very likely to drive higher costs in the long-term due to higher likelihood of failure (and collateral damage) and associated reactive maintenance. Reduction in reactive maintenance results in reduced facility capability and/or capacity. So this process can also be used as a means of advocacy for sustainment of lower ranked, but needed, facility capabilities.

The existing processes for planning and execution of investment recapitalization and capability improvement projects can be improved using the higher fidelity (and quantity) asset information and the prioritization process just described. Improved information in the CMMS will support identification of recapitalization needs gleaned from maintenance results. It is expected that sustainment investments will be robust for block five facilities, will be accomplished selectively for block four facilities, and the improved information will support advocacy for investments for block three assets. The improved understanding of current facility performance and alignment (or not) with near- and long-term mission needs will identify capability gaps required to meet future needs - these gaps are improvement investment opportunities. Thus, investment planning will improve with a better understanding of strategic intent for specific facilities, providing information for gap analyses and associated timeframes.

\begin{tabular}{|c|c|c|c|c|c|}
\hline \multirow{2}{*}{ Maintenance Type } & \multicolumn{5}{|c|}{ Facility Criticality of Need } \\
\hline & 5 & 4 & 3 & 2 & 1 \\
\hline TC Initial Response & Y & Y & Y & Y & Y \\
\hline TC Immediate Problem Fix & Y & Y & Y & $?$ & M \\
\hline Repair (<\$XXk Total) & $\mathrm{Y}^{*}$ & $\mathrm{Y}^{*}$ & $?$ & M & M \\
\hline Repair (>\$XXk Total) & $\mathrm{Y}^{*}$ & $?$ & L & M & M \\
\hline Tactical Engineering Support & Y & $\mathrm{L}$ & M & M & M \\
\hline Preventive Maintenance (PM's) & $\mathrm{Y}^{*}$ & $\mathrm{~L}$ & M & M & M \\
\hline PM Finds --> Treat as repairs & $\mathrm{Y}^{*}$ & $\mathrm{Y}^{*}$ & L & M & M \\
\hline FCA Finds --> Treat as repairs & $\mathrm{Y}^{*}$ & $\mathrm{Y}^{*}$ & M & M & M \\
\hline Predictive Testing \& Inspection (PT\&I) & Y & L & M & M & M \\
\hline PT\&I Finds (try to do these) & Y & L & M & M & M \\
\hline$Y=$ Do the Work & $L=W_{0}$ & Lear & Dow & & \\
\hline ? = Budget Dependent & $M=M i$ & um $\mathrm{V}$ & to $s$ & $\mathrm{n}(\mathrm{o}$ & \\
\hline
\end{tabular}

Figure 9. Notional Table of Maintenance Work in a Budget Constrained Environment. 
In summary:

1. Mission alignment score is defined by combining MDII and RMI scores with adjustment for additional National mission support.

2. Facility performance is defined by combining scoring of FCA (modified by any additional facility equipment condition information) and facility functionality.

3. Criticality (priority) can be relationally defined (likely across a Center) using mission alignment and facility performance.

4. Specific maintenance practices can be tuned (reduced) for lower criticality facilities.

\section{Conclusions and Recommendations}

Much of the infrastructure at NASA Centers is beyond original design life, with degraded conditions compounded by systemically inadequate maintenance. Additionally, since the NACA days, infrastructure was often constructed for specific, program related purposes and then adapted to new purposes as programs evolved. This has resulted in a mix in some facilities (including office buildings) of infrastructure that has been maintained and other that has not; it also has left NASA with a mix of equipment types (such as HVAC equipment), often missing manufacturer's information, and many drawing deficiencies. CMMS information quality is uneven between and within Centers, limiting economies of scale, economic purchasing and delivery of material (including inventory management), efficiencies in scheduling resources to accomplish maintenance, and ability to accomplish timely scheduling of preventive maintenance.

Efforts are ongoing across Centers to accomplish repair by replacement, to improve CMMS usage consistency and information quality, implement FCA's and the MDI process and use them for prioritization of maintenance and investments, and divest poor condition and low-use facilities. But in a time of lean, perhaps even declining, budgets to care for infrastructure, these efforts are insufficient to sustain existing capabilities, even with limited improvement investments for future needs. The existing processes tend to weigh near-term needs and conditions more heavily, potentially lessoning readiness for longer-term (and possibly higher priority) needs. The prioritization process described in this paper will improve management of existing funding so that it can be directed toward the most important facilities to meet NASA's current and long-term missions.

This environment is obviously very difficult and it is driving some hard decisions for NASA leadership. Changes in mission (end of the space shuttle program, cancellation of the Constellation program, initiation of a new space launch system program, and more) also change infrastructure needs and funding sources and availability. This also impacts many people working for NASA that utilize facilities, sometimes creating mismatches between people/skills and physical resources. The following recommendations are divided into two groups; first are items based directly on the subject matter in this paper and the second are related practices that will improve infrastructure management overall.

- Define all assets at a Center at least down to a facility level.

- Continue (or initiate, if not started) systematic facility condition assessments by each Center, to be accomplished on a rotating periodic basis. It is crucial that the information obtained be utilized for equipment management (preferably utilizing the CMMS).

- Continue (or initiate, if not started), systematic assessment of alignment of facilities with mission using a form of the Mission Dependency Index. Accomplish this for all Center facilities.

- Implement the improved mission alignment process described in this paper. The additional consideration of strategic intent and needs will better position each Center to be able to support future missions, while also formally taking additional National needs into account.

- Changes in NASA mission direction must be taken into account over time as this process is used.

- Implement the facility performance assessment process described in this paper. Inclusion of functional performance considerations provides a better assessment of a particular facility's ability to deliver on planned performance.

- Implement this process, over the longer term, across Centers. Potentially very difficult due to regional proprieties, gains from managing the broader asset inventory could be very large. 
- Implement the combined, integrated facility prioritization approach described in this paper at each Center. This provides a prioritized list of importance for every facility at a Center, allowing improved decisionmaking for application of maintenance and investment funding.

- Embrace an integrated enterprise asset management approach for each Center, including a standardized definition of asset hierarchy; equipment grouped into standardized, functional systems; use of a robust CMMS tool integrated into all maintenance, operations, and investment activities; collection, storage (in the CMMS), and use of equipment performance data; and a continuous effort to standardize types of equipment across systems and facilities.

- Utilize a robust systems engineering process for the acquisition of new or significantly updated capabilities

- Develop detailed, performance specification type requirements.

- Ensure any new capability acquisitions or upgrades of existing capabilities are assessed for life cycle needs and associated costs, with new information (maintenance needs, equipment information, and warrantee information) input to the CMMS.

- Manage the Center's suite of facilities as a system.

- Develop/enhance availability of specific smart practices used for sustainment and repair of old infrastructure.

- Conduct a study to develop an alignment tool for: 1) the skills and skill applications (competency areas) of a Center's staff; 2) the available and planned physical infrastructure and associated capabilities; and 3) NASA's current and projected mission needs. Sometimes entrenched staff and changing mission needs cause mismatches across these three areas. This is an ongoing effort within the Agency and is a likely opportunity for improvement.

Full implementation of these recommendations will ensure that the highest priority facility capabilities are sustained to meet near- and long-term needs. It also will introduce efficiencies and better sustainment practices through better use of the CMMS, managing assets holistically (as systems and systems of systems instead of piecemeal), and integrating work across a Center. The funding environment for infrastructure sustainment is likely to become more constrained even as mission needs are changing. At stake is the future viability of NASA core capabilities, so improved processes combined with improved information to help Headquarters and Center management make the right decisions is crucial. 


\section{References}

${ }^{1}$ Morrison, Jim, “Audit of NASA's Facilities Maintenance”, Report No. IG-11-015, memo from Assistant Inspector General for Audits to Woodrow Whitlow, Associate Administrator for Mission Support, March 2, 2011.

"NASA Infrastructure and Facilities: Assessment of Data Used to Manage Real Property Assets", Report No. IG-11-024, report from the Office of Audits, NASA Office of Inspector General, August 4, 2011.

${ }^{3}$ McCreery, Roselyn, taken from a briefing at NASA Langley Research Center, November 18, 2008; derived from figure 9.1 in "Facilities Maintenance and Operations Management", NASA Procedural Requirement 8831.2E, Effective date of November $18,2008$.

${ }^{4}$ Whitlow, Woodrow, Jr., "NASA Facility Strategy", Briefing from the NASA Associate Administrator for Mission Support, dated May 10, 2011, http://www.hq.nasa.gov/office/codej/codejx/Assets/Docs/ConferenceNashville2011/Tuesday/ WhitlowAgencyFacilityStrategy.pdf.

5"Facilities Maintenance and Operations Management", NASA Procedural Requirement 8831.2E, Effective date of November 18, 2008.

${ }^{6} \mathrm{NPR} 8831.2 \mathrm{E}$

${ }^{7} \mathrm{NPR} 8831.2 \mathrm{E}$

${ }^{8} \mathrm{NPR} 8831.2 \mathrm{E}$

${ }^{9}$ NASA IG Audit Report No. IG-11-024.

${ }^{10} \mathrm{NPR} 8831.2 \mathrm{E}$

${ }^{11} \mathrm{NPR} 8831.2 \mathrm{E}$

${ }^{12}$ Teicholz, Eric and Edgar, Alan, "Facility Condition Assessment Practices”, IFMA white paper. Graphic Systems, Inc. 2001. p. 3-5.

${ }^{13}$ Davis, Larry Michael, “A Condition Assessment Process for Aerospace Ground Test Systems”, Master's Thesis, University of Tennessee, Knoxville, December 2009.

${ }^{14}$ Dempsey, Commander James J., "Facility Asset Management Doctrine”, Federal Facilities Council's Forum, October 31, 2006.

15“2011 NASA Strategic Plan”, http://www.nasa.gov/pdf/516579main_NASA2011StrategicPlan.pdf, August 2011.

${ }^{16}$ Antelman, RA Albert, "Mission Dependency Index Deployment", NAVFAC Engineering Service Center, Information Briefing for CNRNE FEC, June 20, 2005.

${ }^{17}$ Dempsey

${ }^{18}$ Gunderson, Steven, Antelman, Al, Canfield, Mary, and Miller, Alex, "The NASA Mission Dependency Index User Guide, Identifying the Relative Importance of Facilities", Version 1.0, Port Hueneme, CA, October 2007.

19،"The NASA Deferred Maintenance Parametric Estimating Guide", Version 5, September 15, 2005.

${ }^{20}$ Loboda, John A. and Sydnor, George H., "FY11 Facility Assessment Study for Aeronautics Test Program", AIAA Aerospace Sciences Meeting, Grapevine, TX, January 2013 (to be published). 


\section{Appendix 1. NASA 2011 Strategic Goals and Outcomes.}

Strategic Goal 1: Extend and sustain human activities across the solar system.

1.1 Sustain the operation and full use of the International Space Station (ISS) and expand efforts to utilize the ISS as a National Laboratory for scientific, technological, diplomatic, and educational purposes and for supporting future objectives in human space exploration.

1.2 Develop competitive opportunities for the commercial community to provide best value products and services to low Earth orbit and beyond.

1.3 Develop an integrated architecture and capabilities for safe crewed and cargo missions beyond low Earth orbit.

Strategic Goal 2: Expand scientific understanding of the Earth and the universe in which we live.

2.1 Advance Earth system science to meet the challenges of climate and environmental change.

2.2 Understand the Sun and its interactions with Earth and the solar system.

2.3 Ascertain the content, origin, and evolution of the solar system and the potential for life elsewhere.

2.4 Discover how the universe works, explore how it began and evolved, and search for Earth-like planets.

Strategic Goal 3: Create the innovative new space technologies for our exploration, science, and economic future.

3.1 Sponsor early-stage innovation in space technologies in order to improve the future capabilities of NASA, other government agencies, and the aerospace industry.

3.2 Infuse game-changing and crosscutting technologies throughout the Nation's space enterprise to transform the Nation's space mission capabilities.

3.3 Develop and demonstrate the critical technologies that will make NASA's exploration, science, and discovery missions more affordable and more capable.

3.4 Facilitate the transfer of NASA technology and engage in partnerships with other government agencies, industry, and international entities to generate U.S. commercial activity and other public benefits.

\section{Strategic Goal 4: Advance aeronautics research for societal benefit.}

4.1 Develop innovative solutions and advanced technologies through a balanced research portfolio to improve current and future air transportation.

4.2 Conduct systems-level research on innovative and promising aeronautics concepts and technologies to demonstrate integrated capabilities and benefits in a relevant flight and/or ground environment.

Strategic Goal 5: Enable program and institutional capabilities to conduct NASA's aeronautics and space activities.

5.1 Identify, cultivate, and sustain a diverse workforce and inclusive work environment that is needed to conduct NASA missions.

5.2 Ensure vital assets are ready, available, and appropriately sized to conduct NASA's missions.

5.3 Ensure the availability to the Nation of NASA-owned, strategically important test capabilities.

5.4 Implement and provide space communications and launch capabilities responsive to existing and future science and space exploration missions.

5.5 Establish partnerships, including innovative arrangements, with commercial, international, and other government entities to maximize mission success.

Strategic Goal 6: Share NASA with the public, educators, and students to provide opportunities to participate in our Mission, foster innovation, and contribute to a strong national economy.

6.1 Improve retention of students in STEM disciplines by providing opportunities and activities along the full length of the education pipeline.

6.2 Promote STEM literacy through strategic partnerships with formal and informal organizations.

6.3 Engage the public in NASA's missions by providing new pathways for participation.

6.4 Inform, engage, and inspire the public by sharing NASA's missions, challenges, and results. 
Appendix 2. Example Application of the Process to a Variety of Facility Types.

\begin{tabular}{|c|c|c|c|c|c|c|c|c|}
\hline \multirow[b]{3}{*}{ Facility Description } & \multirow[b]{3}{*}{ Asset Type } & \multirow[b]{3}{*}{ Customers } & \multicolumn{6}{|c|}{ Mission Alignment } \\
\hline & & & \multicolumn{2}{|c|}{ MAI } & \multirow[b]{2}{*}{$\begin{array}{c}\text { MDI } \\
\text { Score }\end{array}$} & \multirow{2}{*}{$\begin{array}{c}\text { Add } \\
\text { Points } \\
\text { for } \\
\text { National }\end{array}$} & \multirow[b]{2}{*}{$\begin{array}{l}\text { Mission } \\
\text { Score }\end{array}$} & \multirow[b]{2}{*}{$\begin{array}{c}\text { Quintile } \\
\text { on Roll- } \\
\text { up List }\end{array}$} \\
\hline & & & $\begin{array}{c}\text { Specific } \\
\text { SP } \\
\text { Outcome }\end{array}$ & $\begin{array}{l}\text { RMI } \\
\text { Score }\end{array}$ & & & & \\
\hline Transonic high Reynolds number wind tunnel & Mult bldgs. & $1,2,3,4$ & 4.2 & 4 & 85 & yes & 360.0 & 5 \\
\hline Hypersonic wind tunnel & Rooms in a bldg. & $1,2,3,4$ & 4.2 & 3 & 65 & yes & 205.0 & 3 \\
\hline Material laboratory & Room in a bldg. & 1 & 5.3 & 3.5 & 80 & no & 280.0 & 4 \\
\hline Office building & Building & 1 & 5.2 & 2.75 & 55 & no & 151.3 & 2 \\
\hline Electrical grid & Distributed & 1 & 5.2 & 4 & 90 & no & 360.0 & 5 \\
\hline Compressor station & Bldg. + outside & 1 & 5.3 & 4 & 88 & no & 352.0 & 5 \\
\hline Acoustic wind tunnel & Building & $1,2,3,4$ & 4.2 & 2.5 & 40 & no & 100.0 & 2 \\
\hline Multi-use bldg (mixed labs, common use, offices) & Building & 1 & 5.2 & 3 & 75 & no & 225.0 & 3 \\
\hline
\end{tabular}

\begin{tabular}{|c|c|c|c|c|c|c|c|c|c|}
\hline \multirow[b]{3}{*}{ Facility Description } & \multicolumn{8}{|c|}{ Facility Performance } & \multirow{3}{*}{$\begin{array}{c}\text { Facility } \\
\text { Priority } \\
\text { Level }\end{array}$} \\
\hline & \multicolumn{3}{|c|}{ Condition Assessment } & \multicolumn{3}{|c|}{ Funct Performance } & \multirow[b]{2}{*}{$\begin{array}{c}\text { Perform. } \\
\text { Score }\end{array}$} & \multirow[b]{2}{*}{$\begin{array}{c}\text { Quintile } \\
\text { on Roll- } \\
\text { up List }\end{array}$} & \\
\hline & $\begin{array}{c}\text { Latest } \\
\text { FCA } \\
\text { Score }\end{array}$ & $\begin{array}{c}\text { Test/Op } \\
\text { Equip } \\
\text { Cond }\end{array}$ & $\begin{array}{l}\text { Average } \\
\text { CA Score }\end{array}$ & $\begin{array}{l}\text { Scheduled } \\
\text { Availability }\end{array}$ & $\begin{array}{l}\text { Product } \\
\text { Quality }\end{array}$ & FP Score & & & \\
\hline Transonic high Reynolds number wind tunnel & 3.85 & 3.7 & 3.775 & 0.88 & 0.95 & 4 & 15.1 & 4 & 5 \\
\hline Hypersonic wind tunnel & 2.9 & 3 & 2.95 & 0.75 & 0.95 & 3 & 8.85 & 2 & 3 \\
\hline Material laboratory & 3.1 & & 3.1 & 0.98 & 0.95 & 5 & 15.5 & 4 & 5 \\
\hline Office building & 3.1 & & 3.1 & 0.99 & 0.9 & 5 & 15.5 & 4 & 5 \\
\hline Electrical grid & 3.4 & & 3.4 & 0.9 & 0.97 & 4 & 13.6 & 3 & 5 \\
\hline Compressor station & 2.5 & & 2.5 & 0.9 & 0.9 & 4 & 10 & 2 & 3 \\
\hline Acoustic wind tunnel & 3.8 & 3.6 & 3.7 & 0.8 & 0.85 & 3 & 11.1 & 3 & 4 \\
\hline Multi-use bldg (mixed labs, common use, offices) & 4.3 & & 4.3 & 0.98 & 0.95 & 5 & 21.5 & 5 & 5 \\
\hline
\end{tabular}

- All "facilities" are to be classified as at the "facility" level of the Center asset hierarchy

- Customers: 1 = NASA, 2 = DoD, FAA, other US govt, 3 = US industry, 4 = US academia. (Foreign customers are special case.)

- Scheduled availability is a measure of actual readiness when scheduled.

- Product quality relates to facility outputs measured against world-class like standards. 